\title{
La nueva directiva europea sobre los medios audiovisuales remueve el mapa de la televisión
}

\author{
Francisco Campos Freire
}

\author{
Profesor Titular de Comunicación Audiovisual y Publicidad. Universidad de \\ Santiago de Compostela
}

\section{Resumen}

La Directiva Europea de la Televisión sin Fronteras, que desde 1989 marca el rumbo de la política comunitaria de la libre competencia, ha sido reemplazada por un nuevo concepto regulador más amplio, que trasciende también al ámbito convergente de los medios y servicios audiovisuales. Sigue siendo uno de sus ejes centrales el principio de la libre competencia, junto a la invocación a la diversidad y pluralidad, aunque en términos no sólo de la lógica económica sino también de la democracia es necesario mayor desarrollo y profundidad. Así, en la UE se abren nuevos debates sobre el pluralismo en los medios de comunicación y la alfabetización digital. Se mantiene el principio de control del país de origen pero la nueva Directiva Europea de Medios Audiovisuales sin Fronteras empuja a los Estados a reformar sus respectivas legislaciones. Una buena ocasión en España para armonizar el compendio de más de un centener de normas, leyes y decretos actualmente vigentes. Y para que, de una vez, salgan adelante las dos leyes generales del Audiovisual y del Consejo Estatal de Medios Audiovisuales junto a la reforma de las respectivas competencias autonómicas.

Palabras clave: Convergencia, concentración, pluralismo, diversidad, medios lineales y no lineales, alfabetización digital 
Las reformas en materia de regulación audiovisual evidencian la necesidad de mayor coordinación a nivel de sus distintos ámbitos competenciales: Unión Europea, Estado y Comunidades Autónomas. En la Unión Europea ha concluído la revisión de la Directiva de la Televisión sin Fronteras y en España, tanto a nivel estatal como autonómico, se ha abierto la reformulación de las competencias en materia de comunicación y audiovisual pero hasta ahora sólo ha avanzado parcial y descoordinadamente. En cualquier caso estos procesos institucionales de revisión reglamentaria van por detrás y más lentamente que las dinámicas tecnológicas, económicas y sociales de la comunicación audiovisual. Dinámicas sobre las que gira la convergencia, concentración, pluralismo, diversidad y alfabetización digital.

Desde hace varias décadas asistimos a un renacimiento de la Retórica, impulsada por la publicación en la década de los 60 del pasado siglo XX del "Tratado de la argumentación: la nueva retórica" de Perelman y Olbrechts-Tyteca. (Mortara Garavelli, 1991, 7). A partir de esta obra, la Retórica despertó de su letargo y extendió sus redes más allá del discurso y del lenguaje. Roland Barthes, su discípulo Jacques Durand y los integrantes del Grupo $\mu$, entre otros, empezaron a sentar la bases de una Retórica Visual, trasladando los conocimientos fraguados durante siglos alrededor del lenguaje y la literatura al terreno de la imagen.

La convergencia de las tecnologías de la información con las telecomunicaciones y con los contenidos abre el acceso al portal de un nuevo sistema mediático de características económicas y sociales más complejas, que se va traduciendo a las estrategias de las organizaciones y a las nuevas políticas y regulaciones de la comunicación. La difusión audiovisual ya no sólo dispone de un espectro radioeléctrico analógico escaso sino de muchos más canales hertzianos digitales, por cable, satélite y ahora también a través de Internet, mediante Protocolo IP. Esta ampliación de redes y tecnologías modifica algunas condiciones de la oferta y de sus modelos de negocio. Pero no sólo en las redes de difusión sino también en los sistemas y equipos de recepción, en los que convergen el televisor con el ordenador y el teléfono móvil. Esta convergencia doméstica puede traducirse en una especie de centro multimedia de servicios integrados del hogar.

Junto a los tradicionales radiodifusores surgen nuevos operadores de plataformas de integración de canales y de servicios así como nuevos modelos de negocio. De la oferta integrada múltiple de canales de televisión se ha pasado a un nuevo empaquetamiento de servicios de telecomunicaciones y contenidos bajo lo que actualmente se denomina como triple play; es decir, por un único abono de pago, llamadas de teléfono, conexión a Internet y televisión. Este modelo es 
propio y característico de los operadores de telecomunicaciones que, ante el riesgo de competencia de los nuevos servicios de telefonía gratuíta ofrecidos a través de Internet, tratan de agregar más valor a sus ofertas tradicionales mediante la incorporación de televisión y contenidos audiovisuales. Pero la alternativa de Internet, que crece a medida que aumenta la capacidad de su red de banda ancha, no se resigna y abre nuevas posibilidades de comunicación. Frente a la difusión lineal de flujo, que es inherente a las redes convencionales de radiodifusión y televisión, surge también la distribución de stock, a la carta, bajo demanda, al albedrío y medida de cada usuario.

Los modelos que ofrecen los distintos sistemas de difusión, tipos de operadores y tecnologías combinan las ofertas generalistas con las temáticas, financiadas a través de las subvenciones públicas y la publicidad o del pago mediante abono y por consumo. Los sistemas terrestres, cable y satélite responden al modelo de televisión de flujo de carácter lineal mientras que el canal de Internet es el que presenta las condiciones adecuadas para los servicios a la carta o bajo demanda, con interactividad, hipermedia y participación incluída. La televisión por Internet y por móvil rompe el concepto tradicional de radiodifusión broadcast de flujo (de un emisor para muchos receptores) en favor del modelo editorial (catálogo). Pero también supera el ámbito restrictivo del espectro radioeléctrico administrativamente regulado. La emisión por Internet y móvil queda totalmente desregulada, exclusivamente ceñida a su responsabilidad editorial. Amplía las posibilidades de ubicuidad del consumo tanto en el tiempo como en el espacio e, incluso, en los equipos de recepción.

\section{MODELOS DE MEDIOS Y SERVICIOS AUDIOVISUALES}

\begin{tabular}{|c|c|c|c|c|c|c|}
\hline $\begin{array}{r}\text { Sistemas de } \\
\text { difusión }\end{array}$ & Tipo de operador & $\begin{array}{r}\text { Tipo de } \\
\text { tecnología }\end{array}$ & $\begin{array}{r}\text { Modelo de } \\
\text { negocio-oferta }\end{array}$ & $\begin{array}{r}\text { Tipo de } \\
\text { consumo }\end{array}$ & $\begin{array}{r}\text { Receptor, lugar } \\
\text { y estancia }\end{array}$ & $\begin{array}{r}\text { Contenidos y } \\
\text { servicios }\end{array}$ \\
\hline Terrestre & $\begin{array}{r}\text { Difusores } \\
\text { públicos/privados }\end{array}$ & $\begin{array}{r}\text { Transición } \\
\text { analógica-TDT }\end{array}$ & $\begin{array}{l}\text { Subvención, } \\
\text { publicidad, } \\
\text { abierto/pago }\end{array}$ & $\begin{array}{r}\text { Generalista, } \\
\text { familiar, poco } \\
\text { segmentado }\end{array}$ & $\begin{array}{r}\text { Televisor, } \\
\text { hogar, familia }\end{array}$ & $\begin{array}{r}\text { Informativos, } \\
\text { entretenimiento, } \\
\text { deportes }\end{array}$ \\
\hline Cable & $\begin{array}{l}\text { Operadores de } \\
\text { telecos privados }\end{array}$ & $\begin{array}{r}\text { Analógica y } \\
\text { digital }\end{array}$ & $\begin{array}{r}\text { Abono, PPV, } \\
\text { triple play }\end{array}$ & $\begin{array}{r}\text { Segmentado, } \\
\text { temático }\end{array}$ & $\begin{array}{r}\text { TV de hogar y } \\
\text { local público }\end{array}$ & $\begin{array}{r}\text { Especiales, } \\
\text { temáticos, } \\
\text { servicios }\end{array}$ \\
\hline Satélite & $\begin{array}{r}\text { Operador de } \\
\text { plataforma }\end{array}$ & $\begin{array}{r}\text { Analógica y } \\
\text { digital }\end{array}$ & $\begin{array}{l}\text { Codificado, } \\
\text { abono, PPV }\end{array}$ & $\begin{array}{r}\text { Segmentando, } \\
\text { temático }\end{array}$ & $\begin{array}{r}\text { TV de hogar y } \\
\text { local público }\end{array}$ & $\begin{array}{r}\text { Especiales, } \\
\text { temáticos }\end{array}$ \\
\hline Internet & $\begin{array}{l}\text { Plataformas, } \\
\text { agregadores, } \\
\text { individuales }\end{array}$ & $\begin{array}{r}\text { ADSL, IP } \\
\text { Hipermedia }\end{array}$ & $\begin{array}{l}\text { Triple play, } \\
\text { alquiler, pago y } \\
\text { VOD gratuíto }\end{array}$ & $\begin{array}{r}\text { Personal, bajo } \\
\text { demanda, a la } \\
\text { carta }\end{array}$ & $\begin{array}{r}\mathrm{TV}, \mathrm{PC}, \\
\text { portátil, PDA, } \\
\text { MP3, móvil }\end{array}$ & $\begin{array}{r}\text { Interactividad, } \\
\text { participación, } \\
\text { navegación }\end{array}$ \\
\hline
\end{tabular}

Fuente: Elaboración propia

Seis grandes tendencias sacuden con fuerza los sistemas de información y comunicación tanto a nivel global como en nuestros ámbitos locales: Convergencia tecnológica, económica e industrial a través del sistema digital; multiplicación de canales y proveedores de contenidos y servicios que, a la vez, se concentran en ofertas conjuntas y operadores integrados o con 
participación cruzada; fragmentación, reestructuración, transformación, integración y concentración de las cadenas de valor de las distintas organizaciones; revisión y reformulación de los marcos específicos de los derechos de propiedad (de creación y autor) y del capital intelectual de las organizaciones; reemisión y reutilización a través de muchas ventanas de los mismos contenidos y formatos, con pocas alternativas para la creatividad innovadora; y necesidad de calidad de recepción, uso y participación, a través de las identidades y alteridades de la ciudadanía, en la comunicación como medio de relación social democrática en la sociedad de la información y el conocimiento.

Los efectos de la convergencia de tecnologías, redes de comunicación, producción y distribución de contenidos alargan y diversifican cada uno de los eslabones que forman la cadena de valor del ecosistema audiovisual. El concepto de cadena de valor, que es una aportación del economista norteamericano Michael Porter (1986, 33), representa las distintas actividades (eslabones) que una empresa o sector desarrollan a través de sus procesos productivos. Esta secuencia resultaba plausible en el sistema industrial tradicional y también en la llamada economía informacional o electrónica, la surgida entre mediados de la década de los 70 y principios de los 80 . Sin embargo en la nueva economía de la convergencia y las redes de comunicación, las relaciones son más complejas y diversas, lo que genera procesos más parecidos a un ecosistema que a una cadena unidireccional.

Un análisis reciente del profesor Juan Carlos Miguel de Bustos (2007) apunta también seis factores interrelacionados en la nueva economía de las redes: inclusión del consumidor en la cadena de valor; intermediación directa entre oferta y demanda; nuevas mediaciones propiciadas a través de navegadores y comunidades virtuales; nuevos modelos de financiación y de remuneración de los contenidos; cambios estructurales en los productos; nuevos modelos de precios; y nuevas estrategias de los agentes y actores. La omnipresencia de Internet en las actividades económicas propicia cambios en los procesos, flujos y productos que le confieren características singulares a este tipo de intercambio de bienes. El efecto red hace que un bien o servicio tenga un valor para un consumidor potencial que depende del número de consumidores que ya lo poseen. Las estimaciones consideran que el valor total de un bien o servicio con un efecto red es aproximadamente proporcional al cuadrado del número de consumidores que ya poseen ese bien o utilizan ese servicio (PWC, 2006).

La convergencia es un concepto amplio, genérico y bastante ambiguo (Garnham, 1994) que necesita más precisión y calificativos. La convergencia puede ser de carácter tecnológico, 
empresarial, de contenidos o servicios. Burgelman (1995) la define como "la reunión de dos mundos de comunicación (telecomunicaciones y audiovisual) que gracias a la informática pueden converger en tres niveles: tecnológico, de actores y de servicios". Pero lo relevante no es sólo el proceso sino el resultado y sus efectos. Es decir, los efectos de la convergencia en la sociedad y sobre el pluralismo mediático. Por una parte propicia la concentración e integración de servicios y por otra multiplica las posibilidades de incremento de la oferta tanto a través de la televisión digital como mediante las nuevas redes difundidas por la banda ancha e Internet. Pero ni una ni otra de esas consecuencia son automáticamente malas ni buenas. Depende de los resultados de su aplicación social.

\section{REGULACIÓN DE LA CONVERGENCIA}

En ese contexto de la convergencia digital surge la nueva Directiva Europea de los Servicios Audiovisuales, que sustituye a la conocida como la de la Televisión sin Fronteras (DTVSF 89/552/CE), aprobada en 1989 y renovada sucesivamente en dos ocasiones posteriores. Esa orientación de la convergencia marca el cambio ampliando el concepto de televisión al de servicios audiovisuales sin fronteras. También a efectos conceptuales y reglamentarios diferencia entre servicios lineales (emisión continuada de programas de flujo) y no lineales (vídeo y televisión bajo demanda, de catálogo, es decir cuando los usuarios acceden y descargan lo que les interesa); la combinación de los modelos de flujo y del sistema editorial, en definitiva. La nueva normativa comunitaria abarca a todo tipo de comunicación audiovisual (incluída la televisión a través de móvil), independientemente de su canal de distribución. Sin embargo la nueva regulación es mucho más básica y flexible para los servicios no lineales que para los lineales.

La nueva normativa comunitaria se presenta como una respuesta a la evolución tecnológica para la creación en Europa de condiciones de competencia equitativas para los servicios audiovisuales emergentes (vídeo a la carta, televisión móvil y servicios audiovisuales a través de la televisión digital). Sus principios enunciativos se orientan a favor de la libre competitividad, la diversidad cultural, la protección de los menores, la defensa de los consumidores, el pluralismo en los medios de comunicación, la lucha contra la incitación al odio racial o religioso, la apertura a nuevas formas de publicidad, la promoción de obras europeas y producciones independientes así como la recomendación a los Estados miembros para que se garantice la independencia de las autoridades de regulación audiovisual. Este último aspecto y el de la inconcreción en la ayuda a 
la producción audiovisual, sobre todo en lo que se refiere a los servicios no lineales, han sido los más debatidos y los que despiertan mayores reticencias.

La revisión de la Directiva de la Televisión sin Fronteras fue iniciada por la Comisión Europea el 13 de diciembre de 2005. Tras un primer examen en mayo de 2006, el 13 de noviembre de ese mismo año el Consejo Europeo aprobó el proyecto de la nueva Directiva, que pasó al Europarlamento, para su relectura y aprobación. El 12 de febrero de 2007 un Consejo informal celebrado en Berlín preparó el terreno para la ratificación definitiva. Es una revisión precedida de abundante doctrina y literatura comunitaria, como por ejemplo el llamado Libro Verde sobre la Convergencia de los sectores de Telecomunicaciones, Medios de Comunicación y Tecnologías de la Información sobre sus consecuencias para la regulación desde la perspectiva de la sociedad de la información (1997). Diez años después de la última revisión de la Directiva de la Televisión sin Fronteras (TVSF) y del mencionado Libro Verde, la reforma comunitaria trata de asentar nuevas vías de acceso a la convergencia audiovisual.

Los tres ejes de esta reforma de la Directiva de la TVSF son: garantía y preservación de viejos y nuevos derechos afectados por el crisol de la convergencia y los diversos modos de expresión y difusión, nuevas formas de comunicación y publicidad que demandan los mercados y las nuevas tecnologías digitales y la problemática de la convergencia como núcleo de la sociedad de la información. La nueva Directiva mantiene una filosofía regulatoria “de mínimos” en pro del dearrollo competencial de los Estados; es decir, establecidas las grandes líneas maestras, corresponde a los siguientes escalones jurídicos -estatales y autonómicos o locales, según el reparto de competencias- aplicar las trasposiciones de la norma comunitaria a sus respectivas leyes.

La Directiva entiende los servicios audiovisuales como aquellos que son desarrollados por un prestador de servicios de medios que tiene la responsabilidad editorial de proporcionar programas de imágenes en movimiento, acompañadas o no de sonido, con el objeto de informar, entretener o educar al público en general a través de redes electrónicas y/o comunicaciones comerciales audiovisuales. Esta definición no incluye a la prensa en formato electrónico ni a los servicios en los que el contenido audiovisual es meramente accesorio y no constituye su objetivo principal. Pero sí están englobados todos los servicios audiovisuales de medios de comunicación de masas cuyo contenido sea idóneo para la radiodifusión televisada independientemente de la plataforma de difusión, tanto si la concepción editorial y la responsabilidad del prestador se plasman en un horario de programación como en un catálogo de selección. Sin embargo su alcance está limitado a los 
servicios tal como están definidos en el Tratado y, por lo tanto, abarca todas las formas de actividad económica, incluídas las empresas de servicio público.

El prestador de servicios audiovisuales está definido como la persona física o jurídica que ostenta la responsabilidad editorial sobre la elección del contenido audiovisual del servicio de medios audiovisuales y determina la manera en que se organiza dicho contenido. Esta definición no incluye a las personas físicas o jurídicas que simplemente transmiten contenidos cuya responsabilidad editorial compete a terceros. Considera programa al conjunto de imágenes en movimiento, acompañadas o no de sonido, que constituye una entidad individual dentro de un horario o en un catálogo elaborado por un prestador de servicios de medios.

Los servicios lineales y no lineales son distintos tanto por la concepción de su programación como por la capacidad de elección y control que el usuario puede establecer sobre ellos. Sobre esa base la nueva doctrina comunitaria concluye que la incidencia sobre la sociedad será diferente y, por lo tanto, su regulación también puede ser más o menos liviana. La mayor incidencia corresponde a los servicios lineales, aunque la normativa comunitaria reconoce que los no lineales tienen potencial para sustituir a aquellos. Los servicios lineales son aquellos en los que se transmite una secuencia cronológica de programación determinada por un radiodifusor a un número indeterminado de espectadores potenciales. Los servicios de medios no lineales se componen de una oferta de contenidos audiovisuales editados o elaborados por un prestador de medios y en los que los usuarios solicitan, de manera individual, la transmisión de un programa determinado seleccionado entre una gama de contenidos de un catálogo de archivo.

La Directiva introduce también la definición de comunicación comercial audiovisual como las imágenes en movimiento, con o sin sonido, que se transmiten como parte de servicios de medios audiovisuales o, en el caso de los canales temáticos de televenta, como un servicio de medios audiovisuales con el fin de promocionar, de manera directa o indirecta, los servicios o la imagen de una persona física o jurídica dedicada a una actividad económica. Con respecto a la publicidad contempla la integración de productos y colocación de temas dentro de los argumentos cinematográficos y de ficción, patrocinio, telepromoción y una regulación más flexible para la emisión de anuncios que en la Directiva de 1989. La nueva Directiva da entrada a la publicidad de colocación de productos, como toda forma de comunicación comercial audiovisual consistente en incluir o referirse a un producto, servicio o marca comercial de manera que figure en un servicio de medios audiovisuales, con o sin una remuneración o contraprestación similiar destinada al prestador de servicios de medios. 
La flexibilidad de la emisión publicitaria permitirá a las cadenas muchos más bloques y saturación de anuncios, siempre y cuando se mantenga el porcentaje del 20 por ciento por hora, es decir no más de 12 minutos, y cortes no inferiores a 30 minutos en películas, programas infantiles y actualidad informativa. El emplazamiento de productos ha sido autorizado en todo tipo de programas salvo en informativos, infantiles, espacios de consejos y documentales aunque los emisores deberán advertir al principio y al final de cada programa la inclusión del "product placement". En general las emisiones de publicidad y televenta deberán seguir siendo separadas e indentificadas para su diferenciación del contenido editorial.

El incremento de la publicidad, como recurso económico crítico de financiación del sistema audiovisual, refleja la tensión de la estructura de programación y emisión de la televisión convencional actual, tanto de carácter público como comercial. El incremento de operadores, de competencia y de fragmentación de audiencias gravita sobre la misma cuestión. La evolución de la emisión de publicidad en las cadenas españolas de televisión a lo largo de diez años muestra con claridad meridiana esa tendencia.

EMISIÓN PUBLICITARIA DE TV, 1995-2005

\begin{tabular}{|c||c|c|}
\hline 1995 & 948.597 spot & 332.937 minutos \\
\hline 1996 & 1.008 .221 & 413.357 \\
\hline 1997 & 1.200 .255 & 455.419 \\
\hline 1998 & 1.313 .405 & 506.467 \\
\hline 1999 & 1.434 .180 & 506.425 \\
\hline 2000 & 1.470 .378 & 542.001 \\
\hline 2001 & 1.588 .023 & 627.151 \\
\hline 2002 & 1.806 .628 & 741.436 \\
\hline 2003 & 2.111 .071 & 768.765 \\
\hline 2004 & 2.214 .095 & 755.479 \\
\hline 2005 & 2.264 .813 & \\
\hline
\end{tabular}

Fuente, Anuario TNS (2006)

La nueva norma comunitaria trata, por su parte, de mantener el espíritu del objetivo europeo de promoción de las nuevas herramientas de la sociedad de la información y de la industria audiovisual de los contenidos. Pero sus directrices se quedan a mitad de camino porque, aún reconociendo la importancia decisiva de los servicios no lineales para el desarrollo audiovisual y de la producción independiente, no se atreve a dar el paso de la concreción de un compromiso de inversión por parte de esos nuevos operadores de televisión a la carta. Esa inconcreción mereció las reticencias de los sectores directamente implicados en la producción, quienes ya lograron impulsar 
en Cannes en 2006 la Carta Europea del Cine Digital. Este documento es el primer acuerdo mundial que se propone como objetivo para convertir el futuro del cine digital en un éxito comercial a través de una amplia oferta de películas, servicios de fácil acceso para los usuarios, protección adecuada de los derechos de propiedad intelectual, colaboración en la lucha contra la piratería y licencias con certificados de autorización de multiterritorialidad para favorecer la dimensión paneuropea de las obras cinematográficas.

\section{CONCENTRACIÓN, PLURALISMO Y DIVERSIDAD}

La preocupación del Consejo de Europa, de colectivos profesionales y cívicos sobre la concentración, el pluralismo y la diversidad también trata de reflejarse en el espíritu de la nueva Directiva aunque, en los aspectos esenciales e instrumentales, no trasciende más allá de la declaración intencional. La recomendación del Consejo de Europa (2000) sobre el pluralismo en los medios de comunicación insta a los Estados a establecer autoridades de regulación del sector de la radiodifusión que sean independientes del poder político y económico, elegidas de manera democrática y transparente, dotadas de independencia financiera, con poderes y competencia para concesión de licencias, vigilancia, seguimiento y regulación de las obligaciones de los radiodifusores en general así como la asunción de las funciones propias de los órganos de control de los entes públicos, respetando siempre su independencia editorial y autonomía institucional.

La Directiva asume el espíritu de la recomendación pero no concreta más allá sobre las vías ulteriores de regulación, sobre todo con respecto a la naturaleza y alcance de tales órganos independientes; es decir, si deben ser de carácter convergente e integrado o de separación entre tecnología y contenidos audiovisuales. La tesis europea dominante es la de la separación, la del modelo del Consejo Audiovisual de Francia y la sostenida por el Libro Verde de la Convergencia de 1997. El modelo convergente es el británico, representado a través del OFCOM (2003), que integra en una única institución a las distintas actividades relacionadas con las comunicaciones.

La práctica totalidad de los estados europeos -con la excepción de España- disponen de órganos independientes de regulación audiovisual, aunque siguiendo tres modelos distintos. El primero de ellos es el del Consejo del Audiovisual francés, que es el que tomaron las Comunidades de Cataluña, Navarra y Andalucía para la aprobación de sus respectivos órganos autonómicos. Otras Comunidades Autónomas españolas han incluido en la reforma de sus Estatutos de Autonomía la previsión de creación de sus Consejos Audiovisuales. Pero a nivel estatal España aún sigue siendo la excepción europea porque aún no ha sido capaz de poner en marcha su Consejo Superior del 
Audiovisual. El segundo modelo es el convergente de la Oficina de Comunicaciones (OFCOM) británica. En otros países, como Italia y Portugal, optaron por fórmulas mixtas a través de Altas Autoridades para la Comunicación y el Audiovisual. Las autoridades reguladoras independientes del audiovisual, unas 49 en representación de 39 países, se agrupan a nivel europeo en la European Platform of Regulatory Authorities (EPRA), creada en 1995 en Malta.

La política comunitaria aborda la competencia, el pluralismo y la diversidad a través del liberalismo económico de la defensa de la competencia. El sector de la comunicación es observado y vigilado a través de los procesos de concentración empresarial y comercial. Uno de los indicadores empleados para ese seguimiento son los índices de concentración, que son fórmulas matemáticas que se emplean para medir que número de empresas tienen mayor o menor cuota de mercado. El índice C1, C2, C3... determina el grado de concentración que posee el primer operador, el primero y el segundo juntos y el primero, segundo y tercero juntos... El Indice Herfindahl (IF) mide las cuotas de cada una de las empresas y el Índice Adelman, también denominado NE, vinculado al anterior, determina el número de empresas que se necesitan en un mercado para alcanzar el grado de concentración.

Pero ese enfoque, que tiene aspectos positivos de lógica económica, no excluye la necesidad de otras miradas más profundas sobre trascendencia, efectos e impacto social de la concentración. Por dos razones básicas, porque las estrategias de crecimiento de las empresas imponen sinergias y políticas financieras ineludibles frente a una economía globalizada; y porque las nuevas formas de diversificación mediática y participación cruzada pueden servir para eludir mucho más fácilmente la tradicional filosofía regulatoria basada en la concentración horizontal. No hay nada más que observar con cierto detalle la estructura de los veinte principales grupos mediáticos europeos, que generan un volumen comercial superior a los 100.000 millones de euros y unos 400.000 empleos. No es lo mismo concentración mediática y editorial por exigencias económicas que concentración mediática con independencia editorial por estrategia económica y comercial.

\section{LOS 20 PRINCIPALES GRUPOS MEDIÁTICOS}

\begin{tabular}{|c|c|c|c|c|c|}
\hline ANK & $\begin{array}{r}\text { G } \\
\text { RUPO }\end{array}$ & $\begin{array}{l}{ }^{P} \\
\text { AIS }\end{array}$ & $\begin{array}{r}S \\
\text { ECTOR }\end{array}$ & $\begin{array}{r}\text { VNTAS } \\
2005\end{array}$ & $\begin{array}{r}\text { EM } \\
\text { PLEADOS }\end{array}$ \\
\hline 1 & $\begin{array}{r}\mathrm{V} \\
\text { ivendi } \\
\text { Universal }\end{array}$ & $\begin{aligned} \text { rancia } & \text { F }\end{aligned}$ & $\begin{array}{r}\mathrm{T} \\
\mathrm{V} \text {, prensa }\end{array}$ & $9.484^{1}$ & $\begin{array}{r}34 . \\
031\end{array}$ \\
\hline
\end{tabular}




\begin{tabular}{|c|c|c|c|c|c|}
\hline 2 & $\begin{array}{r}\text { B } \\
\text { ertelsman }\end{array}$ & lemania $^{A}$ & $\begin{array}{r}\mathrm{T} \\
\mathrm{V}, \text { Prensa }\end{array}$ & $7.890^{1}$ & $\begin{array}{r}88 . \\
516\end{array}$ \\
\hline 3 & $\begin{array}{r}\text { L } \\
\text { agardère }\end{array}$ & $\begin{array}{l}\mathrm{F} \\
\text { rancia }\end{array}$ & $\begin{array}{r}\text { Pr } \\
\text { ensa, defensa }\end{array}$ & $3.013^{1}$ & $\begin{array}{c}30 . \\
000\end{array}$ \\
\hline 4 & $\begin{array}{r}P \\
\text { earson }\end{array}$ & $\begin{aligned} \text { R } & \\
\text { eino } & \\
\text { Unido } & \end{aligned}$ & $\begin{array}{r}\text { Pr } \\
\text { ensa, edición }\end{array}$ & $\begin{array}{r}9 \\
.123\end{array}$ & $\begin{array}{r}32 . \\
000\end{array}$ \\
\hline 5 & $\begin{array}{r}\mathrm{A} \\
\mathrm{RD} / \mathrm{ZDF}\end{array}$ & lemania & $\begin{array}{r}\mathrm{T} \\
\mathrm{V} \text { públlica }\end{array}$ & $\begin{array}{l}8 \\
.022\end{array}$ & $\begin{array}{r}39 . \\
882\end{array}$ \\
\hline 6 & $\begin{array}{r}\mathrm{R} \\
\text { eed Elsevier }\end{array}$ & $\begin{array}{l}\text { R } \\
\text { eino } \\
\text { Unido }\end{array}$ & $\begin{array}{r}\operatorname{Pr} \\
\text { ensa, edición }\end{array}$ & $\begin{array}{r}7 \\
.542\end{array}$ & $\begin{array}{r}36 . \\
500\end{array}$ \\
\hline 7 & $\begin{array}{r}\mathrm{F} \\
\text { inninvest- } \\
\text { Mediaset }\end{array}$ & talia & $\begin{array}{r}\mathrm{T} \\
\mathrm{V}, \\
\text { multimedia }\end{array}$ & $\begin{array}{l}3 \\
.678\end{array}$ & $\begin{array}{r}5.8 \\
44\end{array}$ \\
\hline 8 & $\begin{array}{r}\mathrm{B} \\
\mathrm{BC}\end{array}$ & $\begin{array}{l}\mathrm{R} \\
\text { eino } \\
\text { Unido }\end{array}$ & $\begin{array}{r}\mathrm{T} \\
\mathrm{V} \text { pública }\end{array}$ & $.449^{3}$ & $\begin{array}{r}20 . \\
550\end{array}$ \\
\hline 9 & $\begin{array}{r}\text { W } \\
\text { olters } \\
\text { Kluwer }\end{array}$ & $\begin{array}{l}\text { P } \\
\text { aíses } \\
\text { Bajos }\end{array}$ & $\begin{array}{r}\operatorname{Pr} \\
\text { ensa, edición }\end{array}$ & $\begin{array}{l}3 \\
.400^{3}\end{array}$ & $\begin{array}{r}18 . \\
400\end{array}$ \\
\hline 0 & $\begin{array}{r}\text { I } \\
\text { TV Plc }\end{array}$ & $\begin{array}{l}\text { R } \\
\text { eino } \\
\text { Unido }\end{array}$ & $\begin{array}{l}\mathrm{T} \\
\mathrm{V}\end{array}$ & $.184^{3}$ & $\begin{array}{r}6.2 \\
62\end{array}$ \\
\hline $\begin{array}{ll} & 1 \\
1 & \end{array}$ & $\begin{array}{r}\mathrm{T} \\
\mathrm{F} 1\end{array}$ & $\begin{array}{l}\mathrm{F} \\
\text { rancia }\end{array}$ & $\begin{array}{l}\mathrm{T} \\
\mathrm{V}\end{array}$ & $.873^{2}$ & $\begin{array}{r}3.9 \\
62\end{array}$ \\
\hline $\begin{array}{ll} & 1 \\
2 & \end{array}$ & $\begin{array}{r}\mathrm{F} \\
\text { rance } \mathrm{TV}\end{array}$ & rancia & $\begin{array}{l}\mathrm{T} \\
\mathrm{V}\end{array}$ & $.844^{2}$ & $\begin{array}{r}13 . \\
526\end{array}$ \\
\hline $\begin{array}{ll} & 1 \\
3 & \end{array}$ & $\begin{array}{r}\mathrm{R} \\
\mathrm{CS} \\
\text { MediaGroup }\end{array}$ & talia & $\begin{array}{r}\text { Pr } \\
\text { ensa }\end{array}$ & $.689^{2}$ & $\begin{array}{r}6.0 \\
00\end{array}$ \\
\hline $\begin{array}{ll} & 1 \\
4 & \end{array}$ & $\begin{array}{r}\mathrm{S} \\
\text { anoma }\end{array}$ & inlandia & $\begin{array}{r}\mathrm{M} \\
\text { ultimedia }\end{array}$ & .622 & $\begin{array}{r}16 . \\
885\end{array}$ \\
\hline $\begin{array}{ll} & 1 \\
5 & \end{array}$ & $\begin{array}{c}\mathrm{R} \\
\mathrm{AI}\end{array}$ & talia & $\begin{array}{c}\mathrm{T} \\
\mathrm{V}\end{array}$ & $.594^{2}$ & $\begin{array}{r}11 . \\
857\end{array}$ \\
\hline $\begin{array}{ll} & 1 \\
6 & \end{array}$ & $\begin{array}{r}\text { B } \\
\text { onnier }\end{array}$ & uecia & $\begin{array}{r}\text { Pr } \\
\text { ensa }\end{array}$ & $\begin{array}{l}2 \\
.585^{2}\end{array}$ & $\begin{array}{r}9.6 \\
41\end{array}$ \\
\hline $\begin{array}{ll} & 1 \\
7 & \end{array}$ & $\begin{array}{r}\mathrm{A} \\
\text { xel Springer }\end{array}$ & lemania $^{A}$ & $\begin{array}{r}\text { Pr } \\
\text { ensa }\end{array}$ & $.392^{2}$ & $\begin{array}{r}10 . \\
166\end{array}$ \\
\hline $\begin{array}{ll} & 1 \\
8 & \end{array}$ & $\begin{array}{r}\mathrm{Y} \\
\text { ell Group }\end{array}$ & $\begin{array}{l}\mathrm{R} \\
\text { eino } \\
\text { Unido }\end{array}$ & $\begin{array}{r}\mathrm{Pu} \\
\text { blicaciones }\end{array}$ & $\begin{array}{l}2 \\
.371\end{array}$ & $\begin{array}{r}11 . \\
638\end{array}$ \\
\hline $\begin{array}{ll} & 1 \\
9 & \end{array}$ & $\begin{array}{r}\mathrm{H} \\
\text { oltzbrinck }\end{array}$ & lemania & $\begin{array}{r}\text { Pr } \\
\text { ensa }\end{array}$ & $.086^{2}$ & $\begin{array}{r}13 . \\
782\end{array}$ \\
\hline $\begin{array}{ll} & 2 \\
0 & \end{array}$ & $\begin{array}{r}\mathrm{D} \\
\mathrm{MGT}\end{array}$ & $\begin{aligned} & \mathrm{R} \\
\text { eino } & \\
\text { Unido } & \end{aligned}$ & $\begin{array}{r}\text { Pr } \\
\text { ensa }\end{array}$ & $\begin{array}{l}1 \\
.401\end{array}$ & $\begin{array}{r}18 . \\
000\end{array}$ \\
\hline
\end{tabular}


Fuente: Elaboración propia con datos de memorias y bases de datos sectoriales

El profesor Alfonso Sánchez-Tabernero (2005) ha analizado el mercado televisivo europeo en el contexto de la competencia entre las televisiones públicas y privadas. Según este autor, los países con mayor índice de concentración responden a dos modelos relacionados con una liberalización divergente de sus mercados: por una parte aquellos que la realizaron más tardíamente y donde una o dos compañías públicas aún conservan una posición hegemónica (Austria, Suecia, Noruega); y por otra, aquellos que la realizaron mucho antes y que, al mismo tiempo, no ponen trabas a las operaciones de concentración de carácter privado (Italia y Alemania). En los mercados menos concentrados (España, Gran Bretaña, Francia) destaca la pérdida progresiva de cuota de mercado de los canales públicos y la fragmentación del sector privado. Estos datos no alcanzan, sin embargo, a los mercados audiovisuales de la televisión de pago y de la radio privada donde los índices de concentración son más evidentes.

A futuro, Sánchez-Tabernero intuye que en el terreno audiovisual los países menos poblados tenderán a permitir mayores índices de concentración porque, cuanto menor es el mercado, mayor es la cuota necesaria para alcanzar el umbral de rentabilidad y para favorecer el desarrollo de compañías altamente competitivas. Y la segunda cuestión clave que apunta se refiere a los estatutos de las televisiones públicas, que determinan el tipo de contenidos y su modelo de financiación, sobre lo que aún "no existen líneas de fuerzas homogéneas y las decisiones de los gobiernos nacionales dependen en buena parte de las coyunturas electorales".

El peso económico de las diez primeras televisiones europeas alcanza los 36.147 millones de euros, con un 54\% de la televisión pública (19.350 millones) frente a un $46 \%$ la privada (16.797 millones).

\section{LAS 10 MAYORES TELEVISIONES EUROPEAS}

\begin{tabular}{|c|c|c|c|c|c|}
\hline $\begin{array}{cr} & \text { R } \\
\text { ANK } & \\
& 2 \\
004 & \end{array}$ & $\begin{array}{cc} & \mathrm{R} \\
\text { ANK } & \\
& 2 \\
005 & \\
\end{array}$ & $\begin{array}{r}\text { TELE } \\
\text { VISIONES }\end{array}$ & $\begin{array}{r}\text { P } \\
\text { AÍS }\end{array}$ & $\begin{array}{r}\mathrm{P} \\
\text { ROPIEDAD }\end{array}$ & $\begin{array}{l}\text { F } \\
\text { INANC. } \\
2005 \text { (en } \\
\text { m. euros) }\end{array}$ \\
\hline 1 & 1 & ARD & $\begin{array}{r}\mathrm{A} \\
\text { LEMANIA }\end{array}$ & $\begin{array}{r}\mathrm{P} \\
\text { UBLICA }\end{array}$ & $\begin{array}{r}5 \\
.905^{5}\end{array}$ \\
\hline 2 & 2 & $\mathrm{BBC}$ & $\begin{array}{r}\mathrm{R} \\
\text { EINO } \\
\text { UNIDO }\end{array}$ & $\begin{array}{r}\mathrm{P} \\
\text { UBLICA }\end{array}$ & $.857^{5}$ \\
\hline
\end{tabular}




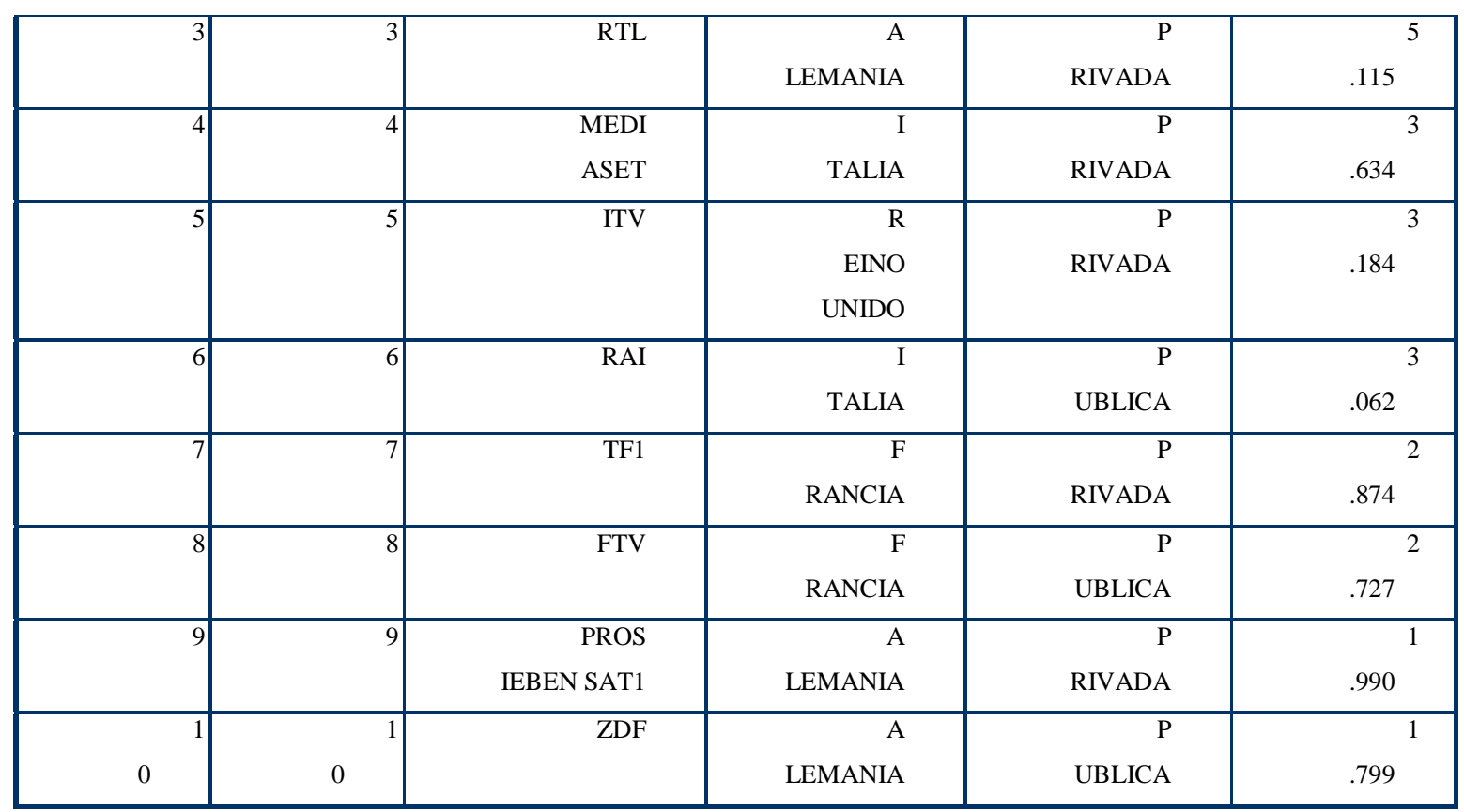

Fuente: Elaboración propia con datos de memorias, e-Media y bases de datos. Los datos de ARD/ZDF son de 2004

El pluralismo está relacionado con la concentración, pero también con la diversidad de los contenidos y la accesibilidad de las distintas expresiones. "El concepto sobre el que pivota el pluralismo es la divesidad" (Llorens-Maluquer, 2001) de contenido editorial, formatos, géneros y programas. Según este mismo autor, la relación entre concentración y pluralismo es indirecta, "una política del pluralismo basada únicamente en leyes anticoncentración (...) puede ser ineficaz al no bardar el pluralismo en sus aspectos de diversidad de contenido". "El nivel donde tenemos que buscar la manifestación real del pluralismo es en la audiencia, en el público, en la sociedad, en el receptor" (Olalla, 2004). Y Juan Carlos Miguel de Bustos (2004) propone como instrumento para el análisis del pluralismo la cadena de valor de la diversidad.

Ese último criterio del pluralismo aplicado a la cadena de valor de la diversidad, no sólo en lo que se refiere a la distribución sino también a la creación y producción, resulta bastante más completo y adecuado para observar la lógica de los servicios audiovisuales. Porque si observamos exclusivamente los datos de la distribución resulta que la Unión Europea presenta actualmente un panorama amplio y diverso de canales, más de 5.000 según recoge a julio de 2006 la nueva base de datos (MAVISE, 2006) del Observatorio Audiovisual Europeo. Contabiliza 14 canales a escala nacional en sistema analógico terrestre; 189 canales nacionales a través de cable, satélite, TDT e IPTV; 1.416 canales nacionales con ventanas de desconexión regional o local; 3.000 canales 
regionales o locales a través de ondas terrestres o cable; 309 canales de mercados de fuera de Europa y 130 de otras distintas tipologías.

Por lo tanto la observación del pluralismo y la diversidad no sólo hay que ampliarlo más allá de su territorialidad, propiedad, tecnología de distribución, especialización de contenidos y formatos sino también a las buenas prácticas de su responsabilidad editorial frente a sus grupos de interés y a la sociedad en general. Es decir, incluir dentro del ejercicio de la responsabilidad social empresarial la medición y evaluación de sus niveles de pluralismo y diversidad, como garantía de calidad frente a la sociedad.

También están aumentando y diversificándose las ofertas de televisión a la carta, lo que la Directiva europea clasifica como servicios no lineales. Un estudio reciente sobre 24 países europeos, realizado por NPA Conseil y publicado por la Direction du Devéloppement des Medies (DDMFrance, 2007), identifica 142 canales de televisión a la carta, de los cuales 94 ofrecen sus servicios a través de Internet, 47 son por IPTV, 11 por cable, seis por satélite y uno a través de TDT. Estos datos verifican con claridad que Internet y, sobre todo la televisión por Internet (IPTV), es el medio hegemónico para los nuevos servicios no lineales. Este mismo estudio identifica tres tipos de actores para este mercado del vídeo bajo demanda: editores de canales de televisión, agregadores de contenidos (empresas y asociaciones de productores, SGAE y EGEDA de España, entre ellos) y operadores de telecomunicaciones. Y tres tipos de modelos económicos on line: Alquiler, compra y VoD gratuíto.

\section{SERVICIOS EUROPEOS DE TV A LA CARTA}

\begin{tabular}{|c|c|c|c|c|c|c|}
\hline Países & $\begin{array}{l}\text { Total } \\
\text { servicios }\end{array}$ & Internet & IPTV & $\begin{array}{l}\text { Cabl } \\
\text { e }\end{array}$ & Satélite & TDT \\
\hline Francia & 20 & 15 & 8 & & & \\
\hline Países Bajos & 19 & 17 & 2 & & & \\
\hline Reino Unido & 13 & 6 & 3 & 3 & 1 & 1 \\
\hline Alemania & 12 & 9 & 3 & & 2 & \\
\hline Bélgica & 10 & 3 & 5 & 5 & & \\
\hline Suecia & 8 & 6 & 5 & & & \\
\hline Italia & 8 & 5 & 3 & & & \\
\hline Noruega & 7 & 6 & 2 & & & \\
\hline España & 6 & 2 & 3 & 1 & & \\
\hline Irlanda & 5 & 5 & & & 1 & \\
\hline Austria & 5 & 3 & 1 & & 1 & \\
\hline
\end{tabular}




\begin{tabular}{|c|c|c|c|c|c|c|}
\hline Finlandia & 4 & 3 & 1 & & & \\
\hline Suiza & 3 & 2 & 1 & & & \\
\hline Polonia & 3 & 1 & 1 & & 1 & \\
\hline Hungría & 4 & 2 & 2 & & & \\
\hline Portugal & 2 & & 1 & 1 & & \\
\hline Estonia & 2 & 1 & 1 & & & \\
\hline Chipre & 2 & & 2 & & & \\
\hline Eslovaquia & 1 & 1 & & & & \\
\hline Islandia & 1 & & 1 & & & \\
\hline Turquía & 0 & & & & & \\
\hline Eslovenia & 0 & & & & & \\
\hline Luxemburgo & 0 & & & & & \\
\hline TOTAL & 142 & 94 & 47 & 11 & 6 & 1 \\
\hline
\end{tabular}

Fuente: DMM-France/Observatorio Audiovisual Europeo

Antes de concluir este apartado, mencionar dos iniciativas europeas de principios del 2007 que también inciden en su preocupación por el pluralismo en los medios de comunicación. Ante la declaración sobre medios y democracia de una coalición de profesionales, organizaciones mediáticas y grupos sociales de carácter civil, la Comisión Europea aprobó un documento de trabajo sobre el pluralismo en los medios de comunicación, un estudio independiente para la evaluación de esta cuestión entre los Estados miembros y la realización en 2008 de una comunicación sobre los indicadores del pluralismo en los medios de comunicación. Hay coincidencia general en que esta preocupación es de crítica importancia para reforzar la libertad, calidad, variedad e integridad de los medios de comunicación y el periodismo en Europa.

\section{ALFABETIZACIÓN AUDIOVISUAL}

Otra tendencia que se advierte entre los expertos y los responsables es la necesidad de avanzar más, no sólo en el análisis crítico de los efectos de la comunicación digital sino también en la pedagogía de su comprensión. Porque si el impacto y efectos son notables en la economía y en los modelos de negocio, no lo son menos en lo que se refiere a la perspectiva general. Lawrence Lessig pone en evidencia la necesidad de una nueva gramática cívica para la sociedad digital, para entender la dimensión audiovisual y multimedia, con especial énfasis y referencia a los públicos infantiles y juveniles como sujetos activos de una nueva alfabetización de carácter global. Lessig resalta 
especialmente la exposición de los niños y los jóvenes a una media de 400 horas de televisión y cerca de 45.000 anuncios comerciales al año.

También la Comisión Europea ha lanzado en octubre de 2006 una consulta pública sobre la alfabetización audiovisual. La Comisaria de la Sociedad de la Información y Medios de Comunicación, Viviane Reding, considera que "la alfabetización audiovisual es tan crucial para el ejercicio de una ciudadanía activa y plena como lo era la alfabetización convencional al comienzo del siglo XIX".

Según Bawden (2002) la alfabetización debe ser "la comprensión, el significado y el contexto" de la sociedad de la información. Para Lanham (1995) significa "la capacidad para entender la información, cualquiera que sea su formato”. Para Wilson (1998) la alfabetización se convierte en mediación profesional: "Nos estamos ahogando en información, mientras que estamos sedientos de saber. De ahora en adelante el mundo estará gobernado por expertos en sintetizar, gente capaz de reunir la información adecuada, opinar críticamente sobre ella, y tomar decisiones importantes e inteligentes". Y mucho antes, para Owens (1976), la alfabetización "es necesaria para garantizar la supervivencia de las instituciones democráticas. Todos los hombres fueron creados igual, pero los votantes con recursos de información están en situación de tomar decisiones más acertadas que los que son analfabetos con respecto a la información”.

La alfabetización audiovisual se refiere a todos los medios de comunicación, incluídos la televisión y el cine, la radio y las grabaciones musicales, medios impresos, videojuegos, Internet y otras nuevas tecnologías digitales de comunicación. La alfabetización audiovisual pretende ayudar a los ciudadanos a discernir hasta qué punto los medios de comunicación filtran las percepciones y las creencias, cómo configuran la cultura popular y en qué medida influyen en las decisiones personales cotidianas. Pretende facilitar competencias de pensamiento crítico y soluciones creativas para los problemas que se les presentan a los ciudadanos en el ejercicio de sus derechos y deberes como consumidores y creadores de contenidos juiciosos.

La alfabetización audiovisual debe promover la libertad de expresión y el derecho a la información, propiciando el fortalecimiento de la democracia. Existe un vínculo entre alfabetización audiovisual y mejora de la legislación, en la medida en que una sociedad alfabetizada en ese aspecto dispone de las competencias necesarias para adoptar sus propias decisiones y definir sus propias 
opciones. El objetivo, en definitiva, que propone la Comisión Europea es hallar las mejores vías para que los ciudadanos y la sociedad en general dispongan de las destrezas necesarias para enfrentarse a los retos de la convergencia y de la sociedad de la información en la mejor posición posible. La consulta pública de la UE, difundida a través de un cuestionario formado por cuatro partes (aspectos generales e iniciativas y proyectos sobre comunicaciones comerciales, creaciones audiovisuales y espacio on line) dará lugar a una comunicación de la Comisión Europea en la segunda mitad de 2007.

En la misma perspectiva, aunque específicamente referida a la industria de los contenidos virtuales, Gran Bretaña ha lanzado también este año la iniciativa del Home Office Task Force on Child Protection on The Internet, un documento de buenas prácticas para promover la seguridad y protección infantil en la red con respecto a servicios de chat, mensajes instantáneos y contenidos digitales. En este documento se invoca, por una parte, la necesidad de un código de buenas prácticas y, por otra, también la necesidad de la alfabetización.

\section{A FALTA DE UN CONSEJO ESTATAL, SEIS AUTONÓMICOS A LA VISTA}

Como se citaba anteriormente, España es una de las pocas excepciones comunitarias negativas en carencia de regulación del pluralismo a través de un órgano audiovisual de carácter independiente. Hubo un intento en 1976, con motivo de la creación de la Comisión del Mercado de las Telecomunicaciones (CMT), de organizar en su seno un capítulo audiovisual "ad hoc", para abarcar aspectos de mayor rango y envergadura que los puramente mercantiles del sector; pero el proyecto no prosperó. Sólo disponen de él tres Comunidades Autónomas: Cataluña, Navarra y Andalucía. En otras dos (Galicia y Madrid) se crearon órganos corporativo-administrativos denominados Consejos Asesores de las Telecomunicaciones y del Audiovisual, pero exclusivamente dependientes de los respectivos gobiernos autonómicos. Las reformas previstas del marco jurídico audiovisual, tanto a nivel del Estado como de las Comunidades Autónomas, prevén un total de siete Consejos Audiovisuales: a los existentes de Cataluña, Navarra y Andalucía hay que añadir los previstos en Valencia, Baleares, Galicia y el de ámbito estatal.

La ley de creación del Consejo Estatal de los Medios Audiovisuales, cuyo informe de solicitud favorable fue aprobado por unanimidad en el Senado en 1995, aún no cristalizó en un proyecto definitivo, a pesar de varios intentos e iniciativas presentadas por los distintos partidos 
políticos ante el Congreso de los Diputados. Varias veces se ha solicitado también su creación desde instancias europeas a través de la Directiva de Televisión sin Fronteras y del Libro Verde de la Convergencia, en 1997, por el Consejo de Europa en el 2000 y ahora, de nuevo, a través de la nueva Directiva de Servicios Audiovisuales.

Desde mediados del 2005 el Ministerio de Industria, Turismo y Comercio tiene elaborado un borrador de proyecto que apuesta por un Consejo Estatal "con amplias competencias, semejantes a las de otras autoridades audiovisuales de países europeos", con obligación de informe vinculante para la concesión de licencias operadoras de radiodifusión, velar por el pluralismo informativo y facultades sancionadoras, entre otras. Propone un Consejo formado por un presidente y seis consejeros, nombrados por seis años (no renovables) por el Gobierno, a propuesta del Congreso de los Diputados, aprobada por mayoría de dos tercios, previa comparecencia parlamentaria de los candidatos para informar de su idoneidad.

El Consejo estatal deberá ejercer sus competencias con independencia del poder ejecutivo y político, responsabilizándose de presentar un informe anual al Gobierno, para enviar al Parlamento, sobre el desarrollo de los medios audiovisuales. El proyecto no prevé competencias ni facultades específicas de coordinación con la Comisión del Mercado de las Telecomunicaciones (CMT) ni con el resto de los Consejos Audiovisuales Autonómicos, aunque sí la posibilidad de suscribir acuerdos y convenios de colaboración. La realidad convergente de los medios de comunicación y el reparto competencial en España hacen imprescindible la concreción de los niveles de responsabilidad y coordinación de los distintos órganos independientes de regulación y control del audiovisual.

Lo que sí se ha acometido en España en la primera parte de la actual Legislatura ha sido la reforma del marco legal de los Medios de Comunicación del Estado, para a continuación afrontar el cambio del modelo de su gestión. La Ley 17/2006 es el nuevo marco legal competente para las relaciones y gestión de los medios de comunicación públicos estatales (Televisión Española, Radio Nacional de España y Agencia Efe). Esa ley ha sido elaborada después del Informe presentado en febrero de 2005 por el Consejo para la Reforma de los Medios de Comunicación de titularidad del Estado, encargado por el Gobierno por Real Decreto 744/2004 de 23 de abril.

El marco competencial estatal del audiovisual en España, sostenido hasta ahora sobre tres bases legales de carácter general y sectorial (Constitución de 1978, Ley 4/1980 de Estatuto de Radio Televisión y Ley 46/1983 del llamado Tercer Canal), se transfería y coordinaba a través de los Estatutos de Autonomía con las respectivas leyes de creación de los entes públicos de radiotelevisión autonómica. El Estado transfería a partir de 1983 a las Comunidades Autónomas, cuando éstas lo requerían, la concesión de la titularidad del tercer canal de televisión, reservándose el control de uso 
y planificación de las telecomunicaciones y del espacio radioeléctrico, en base a su carácter de recurso tecnológicamente escaso (sólo el analógico existente en aquel momento, por supuesto).

Aunque las Comunidades Autónomas asumieron las competencias en materia de comunicación y la mayoría de ellas (País Vasco en 1982, Cataluña en 1983, Galicia en 1984, Valencia en 1984, Madrid en 1984, Canarias en 1984, Baleares en 1985, Navarra en 1985, Aragón en 1987, Andalucía en 1987 y Murcia en 1988) legislaron ya a lo largo de la década de los 80 sobre la creación de sus respectivas radiotelevisiones, sólo las cinco primeras y la andaluza pusieron en marcha las respectivas compañías públicas en ese período.

La televisión central y autonómica nace como monopolio estatal en base a la consideración de servicio público de carácter esencial y a la concesión del espacio radioeléctrico necesario para la difusión de la señal a través de las ondas terrestres hertzianas mediante sistema analógico, un recurso tecnológicamente escaso, que imponía su planificación restrictiva en función de los intereses del Estado. Pero esa limitación tecnológica del espectro radioeléctrico queda superada y rota pocos años después por la irrupción de nuevas emisiones libres a través de cable, satélite y otras tecnologías, en aquel momento reglamentariamente consideradas "piratas" y alegales.

La fundamentación del monopolio estatal sobre el servicio de radio y televisión basándose, entre otros aspectos, en el "recurso tecnológico escaso" decae más adelante también por la jurisprudencia del Tribunal Constitucional y la inevitable apertura que impone el principio de la libertad constitucional de expresión y comunicación. La ley 10/1988 de Televisión Privada abre el monopolio de la radiotelevisión pública en España y da acceso, con el paso del tiempo, a nuevos servicios de difusión a través de satélite, cable y por tecnología digital terrestre. A continuación vendrían la Ley 35/1992 de Televisión por Satélite y la Ley de Telecomunicaciones por Cable y Televisión Local de 1995, que no llegó a ser efectiva (por carencia de reglamento propio) hasta la planificación y adjudicación de las licencias de la televisión digital terrestre local, a partir de 2005, una década después de su promulgación.

\section{MARCO LEGAL AUDIOVISUAL ABIERTO}

La ruptura del antiguo equilibrio competencial entre el Estado y las Comunidades Autónomas se produce a partir de la aprobación de la Ley 22/2005 de Comunicación Audiovisual y la Ley Orgánica 6/2006 del Estatuto de Cataluña, por una parte, y la Ley 17/2006 de Reforma de los Medios de Comunicación Públicos del Estado, que sustituye a la Ley 4/1980 de Radio Televisión, por otro. Cataluña se atribuye competencias plenas en materia de comunicación audiovisual y dominio sobre el espacio radioeléctrico de su ámbito de cobertura territorial mientras que la nueva 
Ley de los Medios de Comunicación Públicos del Estado pierde la condición de norma básica, que tenía la Ley 4/1980, sobre el desarrollo y planificación competencial de carácter autonómico. En medio queda, de momento, en extraño encaje, la Ley 46/1983, conocida como del Tercer Canal; y la radiotelevisión autonómica, que teóricamente sigue sujeta a la concesión del Estado, a través de ese tercer canal, precisamente.

El arco jurídico audiovisual, establecido a partir de la Constitución de 1978, a través de las leyes 4/1980 de RTVE y 46/1983 del Tercer Canal con las Leyes Orgánicas de 1979-81 de los primeros Estatutos de Autonomía, está resquebrajado actualmente. Mientras tanto, varias Comunidades (Canarias, Baleares, Aragón, Asturias, Murcia y Extremadura) desarrollaron desde el 2000 nuevos modelos de radiotelevisión autonómica bajo fórmulas híbridas de gestión semipública. Sin que haya cambiado el marco legal del servicio público, encontramos ya dentro de la radiotelevisión autonómica de España, dos modelos: el de gestión pública directa y el público de gestión híbrida semi-privada, a través de concesiones o externalizaciones más o menos amplias. El primero corresponde a las radiotelevisiones autonómicas creadas antes de finales de la década de los 90 y el segundo a las que se pusieron en marcha a partir del 2000.

Esta descoordinación del marco competencial y legal de la comunicación audiovisual en España aguarda una profunda revisión y reordenación, prometida a nivel estatal en 2004 a través de una Ley General del Audiovisual, de la que aún no se conocen versiones sustanciales y definitivas tres años más tarde. Y así como se ha aprobado la Ley 17/2006 de Reforma de los Medios Públicos del Estado, es necesario un marco general de coordinación estatal y autonómico del servicio público de radiotelevisión. Como también procede la revisión del marco legal de carácter autonómico, consustancial con la reforma de sus nuevos textos estatutarios. Así va en aquellas Comunidades Autónomas más adelantadas en la reforma de sus Estatutos. Reformas que comprenden el significado, reconocimiento e importancia de la comunicación en la sociedad actual para impregnar con ella a sus leyes básicas autonómicas. Sin embargo no está ocurriendo así en todos los procesos de reforma estatutaria abiertos en la mayoría de las Comunidades Autónomas.

Rango y consideración de la comunicación audiovisual no sólo por lo que se refiere a su entramado administrativo, medios de comunicación y recursos sino también por lo que representa como crisol de ejercicio de los derechos de información, participación y accesibilidad que compete a los ciudadanos en una sociedad moderna. El desarrollo de las políticas de comunicación da el nivel de la calidad democrática de una sociedad. La comunicación es una parte muy importante de los derechos sociales de los ciudadanos que reconoce la Constitución y resaltan las Cartas Europeas e 
Internacionales. Aunque el propio marco constitucional los garantiza y protege, no es baladí que también así lo reconozcan, recojan y desarrollen los textos de carácter autonómico.

El reconocimiento institucional y/o creación como órgano de carácter independiente de los Consejos Audiovisuales ha quedado plasmado en el nuevo Estatuto de Autonomía de Cataluña, donde ya existía, como en Navarra, y se ha incorporado el mandado legal de creación en Valencia. También figura reconocido como institución independiente en el nuevo Estatuto de Andalucía, donde ya funciona el Consejo Audiovisual, y se ha incorporado en los nuevos textos que se han debatido en Baleares y Galicia. No figura, en cambio, en los nuevos Estatutos de Aragón y Canarias ni tampoco en la propuesta del País Vasco que fue rechazada por el Congreso de los Diputados en 2005.

El Consejo Audiovisual de Navarra fue creado por Ley Foral 18/2000, de 5 de julio, por la que se regula la actividad audiovisual en dicha Comunidad, como organismo independiente de personalidad jurídica propia. Es la autoridad audiovisual de Navarra y tiene como funciones velar por los contenidos del sector audiovisual, cumplimiento de la legislación vigente, pluralismo de los medios, objetividad y transparencia de la información y cumplimiento de la misión de servicio público de los distintos medios audiovisuales, con facultades sancionadoras, entre otras. Está integrado por un presidente, un secretario y cinco consejeros. Cinco miembros son elegidos por el Parlamento y dos por el Gobierno por mandato de seis años, reelegibles por una sola vez, con renovación cada dos años de un tercio de los mismos.

La Ley Orgánica 1/2006 de reforma del Estatuto de Autonomía de Valencia, junto al reconocimiento de los llamados "derechos emergentes" o ciberderechos relacionados con la sociedad de la información, mandata a las Cortes para la creación por ley y elección por mayoría de tres quintos del respectivo Consejo Audiovisual, "que velará por el respeto de los derechos, libertades y valores constitucionales y estatutarios en el ámbito de la comunicación y los medios audiovisuales en la Comunidad Valenciana”. No tiene, sin embargo, el Consejo Audiovisual valenciano rango de una institución diferenciada como el Síndico de Cuentas, al contrario del que se le atribuye en el nuevo texto estatutario catalán.

El nuevo Estatuto de Cataluña, plasmado en la Ley Orgánica 6/2006, establece a través del artículo 82, en la sección cuarta, después de la Sindicatura de Cuentas y antes del capítulo dedicado el gobierno local, el Consesjo Audiovisual (CAC), como "la autoridad reguladora independiente en el ámbito de la comunicación audiovisual pública y privada. El Consejo actúa con plena independencia del Gobierno de la Generalitat en el ejercicio de sus funciones. Una ley del 
Parlamento debe establecer los criterios de elección de sus miembros y sus ámbitos específicos de actuación".

El CAC es una autoridad independiente, con personalidad jurídica propia, que emana de la Ley $2 / 2000$, por la que fue creada, aunque ahora de nuevo queda remarcada su independencia en el nuevo Estatuto de Autonomía. El CAC está integrado por diez miembros, nueve de los cuales son elegidos por el Parlamento a propuesta, como mínimo, de tres grupos parlamentarios y por una mayoría de dos tercios. El otro miembro, que es el presidente, es propuesto y nombrado por el Gobierno después de escuchar la opinión mayoritaria de los nueve miembros elegidos por el Parlamento. El período de nombramiento es por un solo mandato de seis años, con renovación parcial de un tercio del Consejo cada dos años.

El Consejo Audiovisual Andaluz, creado por Ley 1/2004, está integrado por once miembros elegidos por el Parlamento por mayoría de tres quintos para un período de cinco años, reelegibles por una sola vez y respetando siempre para su designación el principio de paridad de género. El Consejo Audiovisual de Andalucía está reconocido en el capítulo cuarto del texto estatutario, entre la Cámara de Cuentas y el Consejo Económico y Social, como "la autoridad audiovisual independiente encargada de velar por el respeto de los derechos, libertades y valores constitucionales y estatutarios de los medios audiovisuales, tanto públicos como privados, en Andalucía, así como por el cumplimiento de la normativa vigente en materia audiovisual y de publicidad. El Consejo Audiovisual velará especialmente por la protección de la juventud y la infancia en relación con el contenido de la programación de los medios de comunicación, tanto públicos como privados, de Andalucía”.

El Consejo Audiovisual de Baleares lo recoge el artículo 76 de su nuevo Estatuto de Autonomía, dentro del capítulo sexto y de los Órganos de Consulta y Asesoramiento, entre el Consejo Consultivo y el Consejo Económico y Social; "se configura como una entidad pública independiente, cuya misión es velar en los medios de comunicación social de titularidad pública por el cumplimiento de los principios rectores del modelo audiovisual, concretamente: promover las condicions para garantizar la información veraz, objetiva y neutral, y promover la sociedad de la información; garantizar el acceso de los grupos políticos y sociales representativos a los medios de comunicación social; fomentar el pluralismo linguístico en los medios de comunicación; que se cumplan los principios que inspiran el modelo linguístico del Estatuto de Autonomía de Baleares; garantizar y favorecer el acceso de las personas con discapacidad auditiva o visual a los medios de comunicación y a las nuevas tecnologías". 
Los miembros de este Consejo Audiovisual serán nombrados por el Parlamento de Baleares mediante el voto favorable de las tres quintas partes de sus miembros. La composición y las funciones concretas serán desarolladas por una ley del Parlamento. También contempla la nueva regulación estatutaria que el Parlamento de Baleares "será oido preceptivamente para el nombramiento del delegado territorial de cualquier medio de comunicación audiovisual de carácter público con implantación en la Comunidad Autónoma”. Esta facultad no se contempla en ninguno de los otros textos estatuarios, salvo la reserva competencial que Cataluña se atribuye con respecto a todos los medios y sistemas que emitan para el ámbito de su territorio.

Los tres grupos políticos que integran el Parlamento gallego (PP, PSOE y BNG) coinciden en la inclusión del Consejo Audiovisual dentro de la reforma del Esatuto de Autonomía de Galicia, aunque con diferencias sobre las competencias sobre medios públicos y/o privados. No está consensuada tampoco la tasa de dos tercios o tres quintos para el sistema de elección de los miembros del Consejo Audiovisual de Galicia, aunque hay cierta coincidencia con respecto a su consideración como un órgano consultivo de carácter independiente.

Nada prevé al respecto sobre este tipo de órganos la reforma estatutaria aprobada por las Cortes de Aragón. Parcas menciones a los derechos de accesibilidad, un artículo 26 dedicado a la ciencia y la comunicación social y el artículo 68 sobre Medios de Comunicación Social sobre la atribución de competencias y capacidad "para regular, crear y mantener su propia televisión, radio y prensa y, en general, cualquier medio de comunicación social para el cumplimiento de sus fines". Ni siquiera el nuevo título que incorpora esta reforma estatutaria sobre "derechos de los aragoneses" ha considerado que merecían especial y significativa mención los derechos de comunicación. Ni tampoco se los han agregado o incorporado a las disposiciones generales del Justicia de Aragón, como defensor del pueblo y garante de los derechos de los ciudadanos en general.

La preocupación en detalle y mención sobre los derechos de la comunicación en Aragón, Comunidad que dispone sin embargo de una de las primeras leyes autonómicas de publicidad institucional y también de televisión autonómica, tampoco ha estado presente en ninguna de las intervenciones de los cinco portavoces que hablaron el 17 de mayo de 2006 en la sesión parlamentaria de toma en consideración de la propuesta de reforma de la Ley Orgánica 8/1992, de 10 de agosto, de Estatuto de Autonomía, modificada por la Ley Orgánica 6/1994, de 24 de marzo, y por la Ley Orgánica 5/1966, de 30 de diciembre.

Las menciones y referencias a la comunicación en la propuesta de reforma del Estatuto de Autonomía de Canarias, Comunidad que dispone también de radiotelevisión autonómica, se quedan en el régimen general de competencias exclusivas y compartidas, accesibilidad a la sociedad de la 
información y espacio radioeléctrico. En este aspecto, como en el nuevo Estatuto de Autonomía de Cataluña, la Comunidad Autónoma, en el marco del artículo 150.2 de la Constitución española, reclama las facultades del Estado en distintas materias, entre ellas la gestión del "espacio radioeléctrico y telecomunicaciones en el archipiélago canario, sin perjuicio de las competencias estatales en relaciones internacionales".

El proyecto de reforma del Estatuto vasco, también conocido como "Plan Ibaretxe", que fue rechazado por el Congreso de los Diputados, tampoco desarrollaba en lo que se refiere a materias de comunicación y audiovisual grandes diferencias con respecto a su vigente Ley Orgánica 3/1979, salvo en cuanto al ámbito competencial, porque al tratarse de un marco de independencia y "libre asociación”, las facultades y fundamentación correspondían al propio País Vasco. No constaba referencia ni mención a la voluntad, disponibilidad y conveniencia de desarrollo estatutario del Consejo Audiovisual, aunque sí se pone en evidencia su necesidad en los estudios y análisis del profesor Ramón Zallo, algunos de ellos al hilo del informe sobre el audiovisual en el País Vasco.

\section{REFORMAS A DISTINTAS VELOCIDADES}

La reforma del marco legal audiovisual en España se está realizando a distintas velocidades. En el ámbito estatal las dos reformas más importantes corresponden a la Ley 10/2005 de Medidas Urgentes para el Impulso de la Televisión Digital Terrestre de Liberalización de la Televisión por Cable y de Fomento del Pluralismo y la Ley 17/2006 de Reforma de los Medios Públicos del Estado. La primera de ellas podría calificarse más como coyuntural que estructural ya que, si bien por una parte destaca el impulso de la TDT, por otro es la que da carta de naturaleza a la creación de dos nuevos canales analógicos de televisión, mediante la autorización a Sogecable-Prisa para reconvertir su licencia de televisión privada de Canal Plus en una cadena en abierto, bajo la marca de Cuatro, y la concesión de la licencia de la Sexta a un grupo de productoras asociadas junto al grupo mexicano Televisa. La coherencia de esa decisión administrativa ha sido criticada y cuestionada por la mayoría de los otros operadores de televisión por la incomprensible decisión de añadir más competencia en analógico cuando se anuncia el deseo de impulsar el desarrollo de la TDT, cuyo apagón tecnológico ha sido adelantado al 2010.

Las consecuencias de la Ley 17/2006 de Reforma de los Medios de Comunicación Públicos del Estado se han notado en la presentación y negociación del plan de reconversión laboral de RTVE pactado con los sindicatos, en la presión sobre determinados aspectos del control de las inversiones del grupo público, en los efectos sobre la pérdida de sus productos deportivos "estrella" 
y en muy poco más. El nuevo marco legal, por el momento, ni ha servido para aventurar un cambio de rumbo en la orientación del servicio público de televisión ni para erradicar la confrontación política sobre las críticas a la manipulación y falta de pluralismo.

MARCO DE REFORMAS Y COMPETENCIAS AUDIOVISUALES

\begin{tabular}{|c|c|c|c|c|c|c|c|}
\hline Ambito & $\begin{array}{l}\text { Ref } \\
\text { orm } \\
\text { a } \\
\text { de } \\
\text { leye } \\
\text { s y } \\
\text { Est } \\
\text { atut } \\
\text { os }\end{array}$ & $\begin{array}{l}\text { Compete } \\
\text { ncias } \\
\text { audiovis } \\
\text { uales }\end{array}$ & $\begin{array}{l}\text { Conse } \\
\text { jo } \\
\text { Audio } \\
\text { visual }\end{array}$ & $\begin{array}{l}\text { Nú } \\
\text { mer } \\
\text { o de } \\
\text { mie } \\
\text { mbr } \\
\text { os }\end{array}$ & $\begin{array}{l}\text { Sis } \\
\text { te } \\
\text { ma } \\
\text { de } \\
\text { ele } \\
\text { cci } \\
\text { ón }\end{array}$ & $\begin{array}{l}\text { Perí } \\
\text { odo } \\
\text { de } \\
\text { elecc } \\
\text { ión }\end{array}$ & $\begin{array}{l}\text { L.Pub } \\
\text { icidad } \\
\text { Institu } \\
\text { cional }\end{array}$ \\
\hline $\begin{array}{l}\text { ESPAÑ } \\
\text { A }\end{array}$ & $\begin{array}{l}\text { Nue } \\
\text { vas }\end{array}$ & $\begin{array}{l}\text { Ls..10/20 } \\
\text { 05TDT } \\
\mathrm{y} \\
\text { 17/2006 } \\
\text { RTV }\end{array}$ & $\begin{array}{l}\text { Previs } \\
\text { to }\end{array}$ & 7 & $\begin{array}{l}2 / 3 \\
\text { Par } \\
\text { la } \\
\text { m. }\end{array}$ & $\begin{array}{l}6 \\
\text { años } \\
\text { sin } \\
\text { reno } \\
\text { vaci } \\
\text { ón }\end{array}$ & $\begin{array}{l}\text { L. } \\
29 / 200 \\
5\end{array}$ \\
\hline $\begin{array}{l}\text { ANDA } \\
\text { LUCIA }\end{array}$ & $\begin{array}{l}\text { Apr } \\
\text { oba } \\
\text { da }\end{array}$ & $\begin{array}{c}\text { LCA } \\
1 / 2004\end{array}$ & $\begin{array}{l}\text { Funci } \\
\text { ona }\end{array}$ & 11 & $\begin{array}{l}3 / 5 \\
\text { Par } \\
\text { la } \\
\text { m. }\end{array}$ & $\begin{array}{l}5 \\
\text { años, } \\
\text { con } \\
\text { parid } \\
\text { ad } 1 \\
\text { r. }\end{array}$ & $\begin{array}{l}\text { L. } \\
51 / 200 \\
3\end{array}$ \\
\hline $\begin{array}{l}\text { ARAG } \\
\text { ON }\end{array}$ & $\begin{array}{l}\text { Apr } \\
\text { oba } \\
\text { da }\end{array}$ & $\begin{array}{l}\text { De radio } \\
\text { y TV }\end{array}$ & $\begin{array}{l}\text { No } \\
\text { previs } \\
\text { to }\end{array}$ & - & - & - & $\begin{array}{l}\text { L. } \\
16 / 200 \\
3\end{array}$ \\
\hline $\begin{array}{l}\text { BALE } \\
\text { ARES }\end{array}$ & $\begin{array}{l}\text { En } \\
\text { mar } \\
\text { cha }\end{array}$ & $\begin{array}{l}\text { Radio y } \\
\text { TV }\end{array}$ & $\begin{array}{l}\text { Previs } \\
\text { to }\end{array}$ & - & $3 / 5$ & - & $\begin{array}{l}\text { Previst } \\
\text { a }\end{array}$ \\
\hline $\begin{array}{l}\text { CANA } \\
\text { RIAS }\end{array}$ & $\begin{array}{l}\text { En } \\
\text { mar } \\
\text { cha }\end{array}$ & $\begin{array}{l}\text { RTV y } \\
\text { espacio } \\
\text { radioeléc } \\
\text { trico }\end{array}$ & $\begin{array}{l}\text { No } \\
\text { previs } \\
\text { to }\end{array}$ & - & - & - & $\begin{array}{l}\text { Previst } \\
\text { a }\end{array}$ \\
\hline $\begin{array}{l}\text { CATA } \\
\text { LUÑA }\end{array}$ & $\begin{array}{l}\text { Apr } \\
\text { oba } \\
\text { da } \\
\text { L.O } \\
\cdot \\
6 / 20 \\
06\end{array}$ & $\begin{array}{l}\text { Leyes } \\
2 / 2000 \\
\mathrm{y} \\
22 / 2005\end{array}$ & $\begin{array}{l}\text { Funci } \\
\text { ona }\end{array}$ & 10 & $\begin{array}{l}2 / 3 \\
\text { Par } \\
\text { la } \\
\text { m. }\end{array}$ & $\begin{array}{l}6 \\
\text { años, } \\
\text { sin } \\
\text { reele } \\
\text { cció } \\
\mathrm{n}\end{array}$ & $\begin{array}{l}\text { L. } \\
18 / 200 \\
0\end{array}$ \\
\hline $\begin{array}{l}\text { GALIC } \\
\text { IA }\end{array}$ & $\begin{array}{l}\text { En } \\
\text { mar } \\
\text { cha }\end{array}$ & $\begin{array}{l}\text { Radio y } \\
\text { TV }\end{array}$ & $\begin{array}{l}\text { Previs } \\
\text { to }\end{array}$ & - & - & - & $\begin{array}{l}\text { Previst } \\
\text { a }\end{array}$ \\
\hline
\end{tabular}




\begin{tabular}{|c|c|c|c|c|c|c|c|}
\hline $\begin{array}{l}\text { MADR } \\
\text { ID }\end{array}$ & $\begin{array}{l}\text { Pen } \\
\text { dien } \\
\text { te }\end{array}$ & $\begin{array}{l}\text { Radio y } \\
\text { TV }\end{array}$ & $\begin{array}{l}\text { No } \\
\text { previs } \\
\text { to }\end{array}$ & - & - & - & - \\
\hline $\begin{array}{l}\text { NAVA } \\
\text { RRA }\end{array}$ & $\begin{array}{l}\text { Pen } \\
\text { dien } \\
\text { te }\end{array}$ & $\begin{array}{l}\text { Ley } \\
\text { Foral } \\
18 / 2000\end{array}$ & $\begin{array}{l}\text { Funci } \\
\text { ona }\end{array}$ & 7 & $2 / 3$ & $\begin{array}{l}6 \\
\text { años, } \\
1 \\
\text { reele } \\
\text { cció } \\
\mathrm{n}\end{array}$ & - \\
\hline $\begin{array}{l}\text { PAIS } \\
\text { VASC } \\
\text { O }\end{array}$ & $\begin{array}{l}\text { Pen } \\
\text { dien } \\
\text { te }\end{array}$ & $\begin{array}{l}\text { Radio y } \\
\text { TV }\end{array}$ & $\begin{array}{l}\text { No } \\
\text { previs } \\
\text { to }\end{array}$ & - & - & - & - \\
\hline $\begin{array}{l}\text { VALE } \\
\text { NCIA }\end{array}$ & $\begin{array}{l}\text { Apr } \\
\text { oba } \\
\text { da } \\
\text { L.O } \\
\cdot \\
1 / 20 \\
06\end{array}$ & $\begin{array}{l}\text { Radio y } \\
\text { TV }\end{array}$ & $\begin{array}{l}\text { Previs } \\
\text { to }\end{array}$ & - & $\begin{array}{l}3 / 5 \\
\text { Par } \\
\text { la } \\
\text { m. }\end{array}$ & - & $\begin{array}{l}\text { L. } \\
7 / 2003\end{array}$ \\
\hline
\end{tabular}

Fonte: Elaboración propia a partir del seguimiento de la actividad de los distintos Parlamentos.

En el ámbito autonómico, Cataluña es la Comunidad más avanzada en materia de regulación, a través de las leyes 2/2000 del Consejo Audiovisual, 22/2005 de la Comunicación Audiovisual y 6/2006 reforma del Estatuto de Autonomía. En realidad, las materias de comunicación y audiovisual recogidas en la reforma del Estatuto de Autonomía siguen las directrices marcadas por las leyes del Consejo Audiovisual y de la Comunicación Audiovisual de Cataluña. También, en otro aspecto, se podría mencionar que la producción autonómica de leyes de regulación de la publicidad institucional (18/2000 de Cataluña, 51/2003 de Andalucía, 16/2003 de Aragón y 7/2003 de Valencia) se ha adelantado a la aprobación estatal (Ley 29/2005 de Publicidad y Comunicación Institucional del Estado). Leyes sobre la misma materia están previstas también en Galicia, Baleares y Canarias.

\section{CONCLUSIONES}

La aprobación de la nueva Directiva Europea de Servicios Audiovisuales sin Fronteras es una regulación “de mínimos”, fundamentada en el principio de control por el país de origen, que pretende la armonización general comunitaria y que, por lo tanto, presupone su transposición a las respectivas legislaciones de los 27 Estados miembros. Por lo tanto España deberá aplicar, tanto a nivel estatal como autonómico (ámbitos en los que se comparten las competencias) los principios 
generales comunitarios en su nueva producción legislativa. La nueva Directiva comunitaria amplía el concepto de televisión al de servicios audiovisuales y remueve los distintos modelos o tipos de televisión proponiendo dos clasificaciones básicas: servicios lineales (de flujo) y servicios no lineales (catálogo, modelo editorial). La aplicación normativa es más exigente en los primeros y más liviana en los segundos.

Los servicios de televisión bajo demanda, a la carta, están aumentando en el mercado europeo a través de nuevos tipos de operadores y distintos modelos de negocio. Un estudio presentado en Cannes en mayo de 2007 clasifica en Europa 142 canales de televisión a la carta, 94 de ellos por Internet y 47 a través de IPTV. Estos nuevos canales son la televisión por Internet, que rompe con el tradicional modelo de flujo y que es el paso previo a la televisión móvil. Es un modelo de televisión personal y cerrado en su oferta, pero abierto en su regulación. No es necesario ningún tipo de licencia ni autorización para emitir a través de la red. Los nuevos tipos de operadores son: editores de canales de televisión tradicional, agregadores de contenidos (asociaciones profesionales y de autor, EGEDA y SGAE de España, entre ellas) y operadores de telecomunicaciones. Los modelos económicos de oferta on line más comunes son: alquiler por uno o dos días, compra y VOD (descarga) gratuíta.

Los datos cuantitativos sobre el número de canales en Europa -más de 5.000 según una nueva base de datos del Observatorio Audiovisual Europeo- revelan una pluralidad de oferta aunque otra cosa bien distinta sería la evaluación del pluralismo de sus contenidos y, sobre todo, de la accesibilidad a las distintos grupos de interés relacionados con el audiovisual, de la sociedad en general. Por eso, para una adecuada evaluación del pluralismo audiovisual, es acertada la fórmula que propone el profesor Miguel de Bustos del análisis de la diversidad de la cadena de valor, completándola mediante su inclusión en la aplicación y auditoría de la responsabilidad social de empresarial. Es decir, aquí se propone que las empresas asuman los item de la diversidad y el pluralismo dentro de sus estrategias de responsabilidad social corporativa, como garantía de calidad frente a sus stockholders o grupos de interés.

El carácter continuista de la nueva política audiovisual europea sólo roza superficialmente aspectos estructurales y esenciales. Sigue la tradición de la anterior Directiva de la Televisión Sin Fronteras de 1989 y la reserva de las facultades competenciales de los Estados. Define los servicios y los grandes conceptos pero no profundiza en sus raíces. Invoca la libre competencia, el pluralismo, la diversidad y los derechos de los consumidores pero no va más allá de la concentración horizontal ni de la salvaguarda para los usuarios de los nuevos servicios digitales. Ni tampoco ha conseguido el consenso político necesario para concretar porcentajes y obligaciones de ayuda a la producción 
audiovisual independiente a través de los nuevos servicios no lineales, a pesar de que el sector lo consideraba decisivo en su Carta Europea del Cine Digital de Cannes 2006.

El enunciado y tratamiento de algunos de esos aspectos ha servido para abrir nuevos debates e iniciativas europeas, en la mayoría de los casos forzados por la preocupación y sensibilidad de colectivos implicados (profesionales, consumidores, ONG). Por la presión de esas instancias la Unión Europea ha lanzado iniciativas y consultas sobre el pluralismo en los medios de comunicación y la alfabetización en la sociedad digital. Son aspectos cruciales que exigen nuevas visiones, investigaciones y estrategias de actuación al crisol de las nuevas formas de producción y recepción que depara la convergencia tecnológica.

La política audiovisual europea, que se orienta por estas regulaciones y declaraciones, tiene su proyección a través de distintas instituciones (Agencias y Observatorios) y programas (Plan Media 2007-13, eContent, ect) así como a través de la coordinación con las actuaciones de los Estados miembros. A España, además, le corresponde poner al día sin demora su legislación y especialmente cubrir la carencia del Consejo Estatal Audiovisual, que tendría que crearse optando entre un nuevo modelo convergente o específicamente centrado en los servicios audiovisuales, aunque necesariamente coordinado con el otro órgano regulador existente de la Comisión del Mercado de las Telecomunicaciones (CMT) y con los Consejos Audiovisuales Autonómicos.

Un centenar de leyes y decretos conforman el entramado jurídico y regulatorio del sector audiovisual en España. Leyes de distintos ámbitos y épocas producidas por el Estado y por las Comunidades Autónomas, a medida que se iban poniendo en marcha las distintas modalidades audiovisuales, en algunos casos bastante por detrás de ellas (por ejemplo, la regulación efectiva de la televisión local). Se trata en general de una regulación asimétrica y poco homogénea, que en algunos casos resulta incoherente y que necesita una integración y transversalidad evidente para abarcar las distintas áreas, aspectos y diferencialidades que integran el hipersector de la infocomunicación en lo que se ha convertido el audiovisual en este siglo XXI.

Por lo menos siete Consejos Audiovisuales, entre el proyecto estatal y los de carácter autonómico, configuran los planes de reforma en marcha del sistema audiovisual en España. Hay constatación de voluntad para la creación de estos órganos aunque, por el momento, no se ha avanzado en dirección a modelos que contemplen la incuestionable incidencia actual de la convergencia, aún manteniendo la separación competencial de las TIC, y nuevas formas de representación social y ciudadana más allá de la mecánica partidista de las mayorías reforzadas (que también devienen en sistemas de negociación, alianzas y bloqueo cuestionables). 
En conclusión, tres modelos de desarrollo autonómico sobre la comunicación y el audiovisual se están abriendo paso a través de las reformas de los Estatutos de Autonomía: El de máximos de Cataluña marcado por la ruptura con el sistema tradicional compartido de las competencias con el Estado. Es un nuevo marco competencial, que tiende al modelo federal de los lander alemanes, que ostentan todas las competencias en comunicación. El modelo intermedio de Valencia, a partir de las competencias del Estado, desarrolla y promueve nuevas instituciones competenciales como el Consejo Audiovisual. Y el de mínimos marcado por Aragón y Canarias (salvo en lo referido a la reclamación de la gestión del espacio radioeléctrico, en el último caso) con apenas referencias a las nuevas competencias que le corresponden a la comunicación y el audiovisual en la sociedad de la información.

\section{FUENTES Y BIBLIOGRAFÍA}

Bawden, D. (2002), "Revisión de los conceptos de alfabetización informacional y digital”, trad., en Anales de Comunicación, núm. 5, Murcia

Beceiro, S.(2006), “Un largo camino que aún no ha finalizado. Anhelado y polémico Consejo Audiovisual de España”, en Telos, nú. 67, Madrid

Bourdon, J. (2006), "La experiencia internacional de los organismos de regulación. El caso del CSA (Conseill Superiéur de 1'Audiovisuel)", en Telos, núm. 68, Madrid

Burgelman, J.C. (1995), "Convergence et Réseaux transeuropèens- quelques problemes pololitiques" en Norhomme-Fraiture, M., Multimédia. Actes de la journée d'information sur le multimédia”, Namur, Pr. Universitaires

Bustamante, E. (2005), "La radiotelevisión pública en España”, en Telos, núm. 65, Madrid Bustamante, E. (2006), “Un auténtico servicio público garantizado por el Consejo Audiovisual”, en Telos, núm. 68, Madrid

Bustamente, E. (1999), La televisión económica. Financiación, estrategias y mercados, Barcelona, Gedisa Editorial

Camps, V. (2006), “Del Senado a la experiencia del Consejo Audiovisual de Cataluña”, en Telos, núm. 68, Madrid

CMT (2005), Informe anual de la Comisión del Mercado de Telecomunicaciones, Madrid-Barcelona 
Consejo de Europa (2000), "Recomendación sobre el pluralismo en los medios de comunicación", www.humanrigts.coe.int/media/documenst/legal\%20texts/regulatory -auhorties.doc

DDM-France (2007), Etude sur le développement de la vidéo à la demanda dans 24 pays européens, realizado por NPA Conseil, en www.obs.coe.int

Del Corral, J. (2006), "La industria televisiva comercial y las autoridades reguladoras", en Telos, núm. 68, Madrid

Directiva 89/552/CEE de la Televisión sin Fronteras

Ecija Bernal, H. (2000), Libro Blanco del Audiovisual. Como producir, distribuir y financiar una obra audiovisual,

Ecija\&Asociados Abogados, Madrid

Ecija Bernal, H. (2005), Libro Blanco del Audiovisual. Hacia una nueva política audiovisual. Modelos de televisión, regulación de contenidos y consejos audiovisuales en España, Europa y EEUU, Ecija\&Asociados Abogados, Madrid

GAPTEL (2005), Televisión digital, Madrid, en www.red.es

GAPTEL (2006), Contenidos digitales. Nuevos modelos de distribución online, Madrid, en www.red.es

García Castillejo, A. (2006), "Una laguna fundamental del sistema democrático. El Consejo Estatal de Medios Audiovisuales de España”, en Telos, núm. 68, Madrid

Garham, N. (1994), "What is multimedia", 10-15, Legal aspects of multimedia and GIS", Legal Advisory Conference, CE (DG XIII)

Informe para la Reforma de los Medios de Comunicación de Titularidad del Estado (2005), Madrid Lanham R. (1995), Digital literacy, Scientifc American, 273(3), 160-161

Lessing, L. (2005), Cultura libre. Como los grandes medios están usando la tecnología y las leyes para encerrar la cultura y controlar la creatividad, traducción de Antonio Córdoba, $\underline{\text { www.worcel.com/archivos/6/cultura libre_Lessing.pdf }}$

Ley 1/2004 del Consejo Audiovisual de Andalucía, de 17 de diciembre 
Ley 10/1988, de 3 de mayo, de Regulación de la Televisión Privada

Ley 10/2005, de 14 de junio, de Medidas Urgentes para el Impulso de la Televisión Digital

Terrestre, de Liberalización de la Televisión por Cable y de Fomento del Pluralismo

Ley 17/2006 de los Medios de Comunicación Públicos del Estado

Ley 2/2000, de 4 de mayo, del Consejo Audiovisual de Cataluña

Ley 22/2005, de 29 de diciembre, de Comunicación Audiovisual de Cataluña

Ley 4/1980 de Estatuto de la Radio y Televisión

Ley 46/1983 Ley del Tercer Canal

Ley Foral 18/2000 del Consejo y del Audiovisual de Navarra

Ley Orgánica 1/2006 Estatuto de Autonomía de Valencia

Ley Orgánica 3/1979 del Estatuto de Autonomía del País Vasco

Ley Orgánica 6/2006 Estatuto de Autonomía de Cataluña

Libro Verde de la CE sobre la Convergencia de los sectores de Telecomunicaciones, Medios de Comunicación y Tecnologías de la Información sobre sus consecuencias para la regulación desde la perspectiva de la Sociedad de la Información (1997)

MAVISE (2006), A database of all TV companies and channels in 27 EU countries +2 candidate countries, European Audiovisual Observatory, www.obs.coe.int

Miège, B., (1999), “El desplazamiento hacia los contenidos”, 175-196, en Bustamante, E., Monzoncillo, J.M, Presente y futuro de la televisión digital, Madrid, EDIPO

Miguel de Bustos, J.C. (2004), "Sobre pluralismo y diversidad”, en Zer, núm. 16 Modificación de la Directiva 97/36/CE de la Televisión sin Fronteras

Olalla, F.T. (2004), "Revisión crítica de las relaciones entre pluralismo y mercado en los medios audiovisuales", en Zer, núm. 16

Owens, M.R. (1976), State, government and libraries, Library Journal, 101(1), 27

Palacio, M. (2006), “Ciudadanía televisiva y autoridad independiente en España. Un caso excepcional en el contexto audiovisual europeo”, Telos, núm. 68, Madrid Porter, M.E. (1986), Estratégia competitiva. Técnicas para a análise de indústrias e da concorrência, Campus, Rio de Janeiro

Porter, M.E. (1996), ¿Qué es la estrategia?", Harvard Business Review, 11-12 
Ponencia de reforma del Estatuto de Autonomía de Aragón, aprobada en sesión de 17 de mayo de 2006

Ponencia de reforma del Estatuto de Autonomía de Canarias, 2006

Proposición de reforma del Estatuto de Autonomía para Andalucía, aprobada por el Pleno del Parlameno en sesión celebrada el 2 de mayo de 2006

PWC (2006), El crecimiento de los medios para un estilo de vida. Cómo lograr el éxito en la era de la convergencia digital, informes, en www.pwc.com

PWC (2006), Outlook 2020. Un paseo por el sector del ocio y los medios de comunicación, informes de PWC en www.pwc.com

Roca Sales, M. (2007), Derechos de propiedad intelectual e Internet en España. Materiales para un debate informado, Informe de Investigación con el asesoramiento de M. Castellss, UOC, Barcelona

Sánchez-Tabernero, A. (2005), "El mercado televisivo europeo. La competencia entre las televisiones públicas y privadas”, en Telos, abril-junio, número 63, Madrid

Schumann, G. (2006), "La regulación de la radiodifusión en el federalismo: El caso de Alemania”, en Telos, núm. 68, Madrid

Tomás, F. (2006), “Equilibrios internos y externos de los Consejos Audiovisuales. Un nuevo sistema de autoridades para el audiovisual español”, en Telos, núm. 68, Madrid Wilson, E.O. (1998), Consilence; the unity of knowledge, Little, Brown and Co., London

Zallo, R. (2006), “Consejos del audiovisual en las Comunidades Autónomas”, en Telos, núm. 68, Madrid 


\section{$\underline{\text { Abstract }}$}

The new EU directive for the audiovisual media stirs up the legal framework for Europe's TV sector

\section{FRANCISCO CAMPOS}

The "Audiovisual without frontiers" directive that has guided the EU common policy on fair competence since 1989 has been replaced by a newer and broader legal concept that incorporates the convergence of the emerging media and the latest audiovisual services. Fair competence is still one of the central axes of the new directive, with invocation of plurality and diversity, even tough in economic and democratic terms, more development and depth would be still needed.

Discussions have been going on in the EU regarding pluralism in the media and digital alphabetization. The principle of national revision of the directive is preserved, but requires the member countries to adjust their respective laws to the EU guidance.

This creates a good occasion for Spain to compile and harmonize the hundred of rules and decrees that are currently in force. It would be a good opportunity also to approve new general law for the Audiovisual Media and the National Council for the audiovisual sector. As well, it would be positive to revise the division of autonomic competences.

Key words: Convergence, Concentration, Pluralism, Diversity, Lineal and non Lineal Media, Digital alphabetization. 